\title{
Late Migration of a Sideris Buttoned Device for Occlusion of Atrial Septal Defect
}

\author{
Timothy Cotts, ${ }^{1 *}$ MD, Peter J. Strouse, ${ }^{2}$ MD, and Joseph N. Graziano, ${ }^{1}$ MD \\ We describe a 17-year-old patient with an atrial septal defect who underwent device \\ closure with a second generation Sideris buttoned device at 4 years of age. She pre- \\ sented 13 years after the procedure with the acute onset of chest discomfort, at which \\ time a chest radiograph showed migration of the wire of the right atrial counter- \\ occluder to the lateral aspect of the right atrial wall, with an associated right atrial per- \\ foration. The patient underwent uneventful surgical device retrieval and atrial septal \\ defect closure. Late migration of a portion of the Sideris buttoned device can occur, \\ suggesting the need for continued follow up, and a high index of suspicion for device \\ failure should a patient become symptomatic. 2006 Wiley-Liss, Inc.
}

Key words: complications; pediatric catheter intervention; patent foramen ovale; atrial septal defect; pediatric interventions; imaging (CT/MR)

\section{INTRODUCTION}

Trans-catheter closure of atrial septal defects is now widely performed using a variety of devices. In the early nineties, the Sideris buttoned device was used at multiple centers. Early debuttoning of the device is a well-known complication, occurring in $7.2 \%$ of patients [1]. Modification of the device to include two spring buttons decreased the rate of unbuttoning to $0.9 \%$ [2]. Late complications including displacement of the device with increasing shunt and thrombus formation have been reported previously [3,4]. Late embolization of other devices, such as the ASDOS double umbrella device, has also been reported [5]. We report a patient presenting with acute onset of chest discomfort thirteen years following transcatheter ASD closure with a buttoned device, who was found to have embolization of the right atrial counter-occluder of the device. The device failure resulted in perforation of the right atrium, requiring surgical retrieval of the device.

\section{CASE REPORT}

The patient is a 17-year-old young woman, who presented to an outside emergency department with chest discomfort. In March of 1991, at 4 years of age, she underwent device closure of a secundum atrial septal defect (ASD). The defect measured $11 \mathrm{~mm}$ by transthoracic echocardiogram and was sized to $15 \mathrm{~mm}$ using a balloon catheter. Prior to closure of the ASD, her pulmonary artery pressure was $20 / 10 \mathrm{mmHg}$ with a mean of $13 \mathrm{mmHg}$, and a Qp:Qs of 2.1 to 1 . The defect was closed using a $35-\mathrm{mm}$ second generation Sideris Button ASD occluder. Transthoracic echocar- diogram performed during device placement as well as subsequent echocardiograms showed good position of the device, with trace residual shunting at the superior and inferior margins of the device.

She continued to do well, and she was seen in 1994, 3 years after placement of the device. A chest radiograph at that time showed the device to be in good position (Fig. 1A) and was consistent with previous films obtained immediately following device placement. An echocardiogram continued to show trivial residual left to right shunts at the superior and inferior margins of the device. Her next visit was in 1999, at age 12 , ( 8 years postprocedure). At that visit, she continued to be asymptomatic, and her echocardiogram remained unchanged.

She did well until December 2003, when she noted the onset of palpitations, and "an unusual sensation" in her chest. She did not seek medical attention at that time. Six

${ }^{1}$ Division of Pediatric Cardiology, Department of Pediatrics, C.S. Mott Children's Hospital, University of Michigan, Ann Arbor, Michigan

${ }^{2}$ Section of Pediatric Radiology, Department of Radiology, C.S. Mott Children's Hospital, University of Michigan, Ann Arbor, Michigan

*Correspondence to: Timothy Cotts, Division of Pediatric Cardiology, Department of Pediatrics, University of Michigan Health System, L1242 Women's, Box 0204, 1500 East Medical Center Drive, Ann Arbor, MI, 48109-0204. E-mail: cottstim@umich.edu

Received 6 March 2006; Revision accepted 20 May 2006

DOI 10.1002/ccd.20849

Published online 12 October 2006 in Wiley InterScience (www. interscience.wiley.com). 


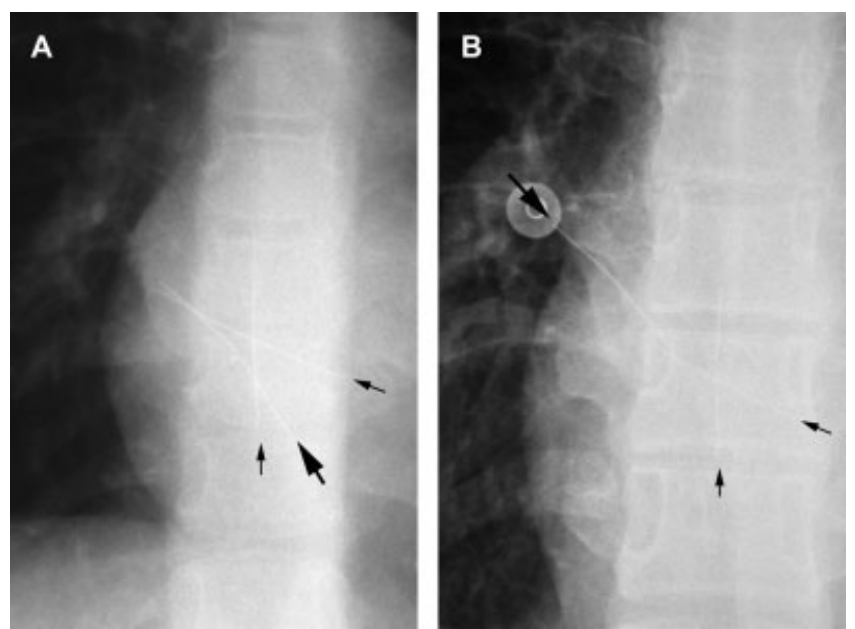

Fig. 1. Chest radiographs taken in 1994 and 2004. A: The chest film taken in 1994 shows the left atrial occluder (small arrows) and the right atrial counter-occluder (large arrow) to be intact and in good position. B: The follow-up study in 2004 demonstrates migration of the right atrial counter-occluder, extending beyond the cardiac silhouette.

months later, now age 17 , and 13 years post-procedure, she presented to an outside emergency department with complaints of acute chest discomfort. The pain was substernal in location, described as " 10 out of 10 " in severity and pleuritic in nature. The oxygen saturation was normal, as was the general physical examination. A chest radiograph showed the device itself to be in position, although the right atrial counter-occluder appeared to have migrated to the right atrial lateral wall extending beyond the heart border (Fig. 1B). The patient was therefore referred to the pediatric cardiology clinic for further evaluation.

An echocardiogram was performed in the clinic, showing no significant pericardial effusion, and no residual atrial shunts. The right atrial counter-occluder was not well visualized. Because of her radiograph findings and symptoms, she then underwent a CT scan of the chest, to better evaluate the position of the device as well as to rule out pulmonary embolism as the etiology of her chest discomfort. The study was negative for pulmonary embolism, but it showed a small anterior pericardial effusion and migration of the wire of the counter occluder through the right atrial lateral wall (Fig. 2A and B). A transesophageal echocardiogram (TEE) was performed later that week to better evaluate the position of the device and counter-occluder, as well as to better assess for any residual atrial level shunts. The TEE showed a moderate pericardial effusion, which had increased in size when compared with that in the transthoracic study performed 1 week earlier. The left atrial portion of the device was noted to straddle the atrial septum, with two arms on the left atrial side and two arms on the right atrial side. There was a $4-5 \mathrm{~mm}$ residual shunt superiorly and a 6-mm shunt low in the primum septum, adjacent to the coronary sinus ostium.

The possibility of transcatheter device retrieval and residual ASD closure was entertained at this time. However, given the acute nature of the pericardial effusion and the low probability for success in transcatheter device retrieval, the patient was referred for surgical removal of the device and ASD closure later the same day.

Intraoperatively, the wire of the right atrial counteroccluder was found to have migrated completely outside the heart and into the right pleural space (Fig. 3). The inset photograph demonstrates an intact counteroccluder. This is in contrast to the the intra-operative photograph showing only the wire skeleton of the counter-occluder. A perforation was noted in the right atrium, just inferior to the superior cavoatrial junction, near the entry of the right superior pulmonary vein. No endothelialized foam was visualized in proximity to the wire skeleton of the counter-occluder or near the site of perforation. The perforation was repaired using a single prolene suture. Assessment of the intracardiac anatomy showed a large residual ASD. The left atrial occluder portion of the device was noted to straddle the atrial septum. As much of the remaining portion of the device was endothelialized and incorporated into the atrial wall, this was left in place. The residual primum septum was multiply fenestrated and was resected. The residual ASD was closed using a Gore-Tex patch. The patient had an uneventful postoperative course. A post-operative echocardiogram revealed no residual ASD. The patient was discharged 4 days later and has continued to do well since.

\section{DISCUSSION}

This case documents the late failure of a Sideris ASD buttoned device. Device failures generally occur early and may be related to the initial positioning of this device [2,6-8]. As this device was found, by TEE, to be straddling the atrial septum, it could be argued that perhaps the initial placement was incorrect. There was no TEE at the time of placement, documenting straddle of the device, though multiple surface echocardiograms demonstrated adequate device position and minimal residual shunt. Straddle of devices across the atrial septum generally resulted in significant residual shunts immediately after placement [2]. Lloyd et al. reported the benefits of transesophageal echocardiography, as opposed to transthoracic echocardiography, for guidance during placement of such devices [9]. It appears possible that in this case, straddling of the device may have been present but not seen by transthoracic imaging. Increased stress placed on the 


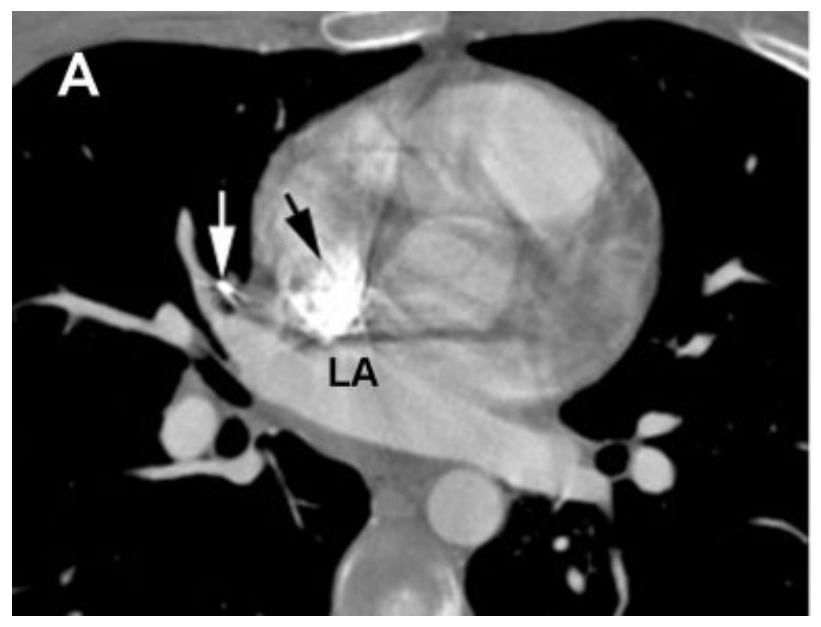

Fig. 2. CT images at the time of symptoms, in 2004. A: Axial CT image at the level of the superior pulmonary veins. The displaced counter-occluder extends beyond the heart border and pericardium, protruding into aerated lung anterior to the anterior division of the right superior pulmonary vein (white arrow). LA, left atrium; black arrow indicates dense contrast at junction of superior vena cava with right atrium. B: Maxi-

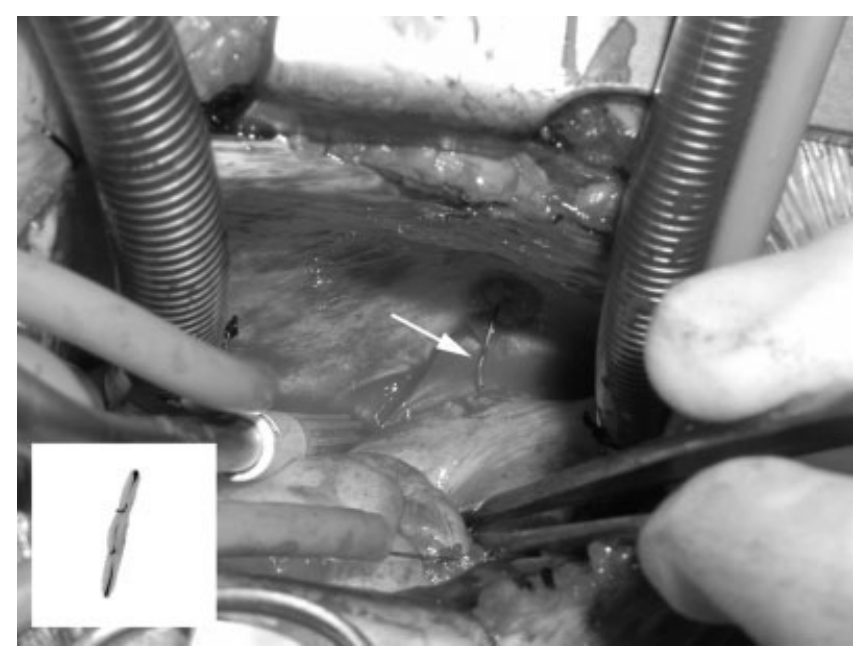

Fig. 3. Intraoperative photograph of the counter-occluder outside the pericardium, with protrusion into the pleural space with surrounding inflammation (arrow). The inset photograph demonstrates an intact counter occluder, including the polyurethane foam coating. This is in contrast to the presence of only the wire in the intra-operative photograph.

counter-occluder over a period of years as a result of initial malpositioning of the device may have resulted in late failure of the device. The second generation devices were in use until 1992. Later devices, including the third and fourth generation devices, incorporated modifications to reduce the possibility of unbuttoning, making the reported complication less likely. Additionally, later devices involved additional suturing of the wire within the counter-occluder, also decreasing the possibility of this complication.

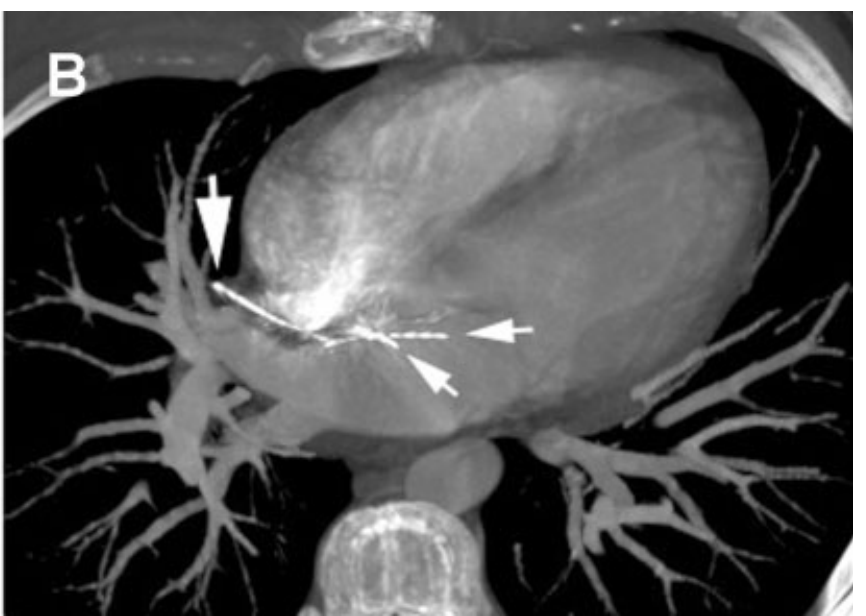

mum intensity projection image produced from a $3.5-\mathrm{cm}$ thick slab tilted slightly oblique from axial to include most of the ASD occlusion device. Small arrows mark the occluder. A large arrow marks the counter-occluder, which has migrated through the right atrium and pericardium, with its tip protruding anterior to the right superior pulmonary vein as it joins the left atrium.

The precise timing of failure of this patient's device cannot be completely known, although it was certainly intact in 1999. It seems possible that the failure occurred relatively acutely, in June of 2004, when the patient first presented with chest discomfort. This is supported not only by the acute symptomatology, but also by the relatively rapid progression to perforation with an enlarging pericardial effusion noted by TEE a week later.

Transcatheter retrieval of failed devices is feasible in some cases, although the general approach to recovery of these devices has been surgical $[8,10,11]$. In this case, an attempt at retrieving the wire skeleton of the counter-occluder and the device as well as repeat device closure was considered. The surgical finding of complete extrusion of the counter-occluder would have precluded successful transvenous retrieval of this portion of the device.

This case illustrates an unusual but important late complication of the Sideris buttoned device. Given the significant number of these devices placed, clinicians should maintain an index of suspicion for late failure of the device, particularly if the patients present with significant cardiac symptoms. Additionally, periodic confirmation of device position by chest X-ray may be a helpful screening tool to detect device failure in those patients without overt symptoms.

\section{REFERENCES}

1. Rao PS, Sideris EB, Hasdorf G, et al. International experience with secundum atrial septal defect occlusion by the buttoned device. Am Heart J 1994;128:1022-1035. 
2. Rao PS, Berger F, Rey C, et al. Results of transvenous occlusion of secundum atrial septal defects with the fourth generation buttoned device: Comparison with first, second and third generation devices. J Am Coll Cardiol 2000;36:583-592.

3. Lambert V, Losay J, Piot JD, et al. Late complications of percutaneous closure of atrial septal defects with the Sideris occluder. Arch Mal Coeur Vaiss 1997;90:245-251.

4. Gaul C, Heckmann JG, Bremer J, et al. Thrombus attached to a Sideris septal occluder system 6 years later. Dtsch Med Wochenschr 2004;129:87-90.

5. Kabus M, Nachtrodt G, Lorenz N, et al. Late complications after transcatheter closure of atrial septal defect. Z Kardiol 2001;90: 516-521.

6. Chessa M, Carminati M, Butera G, et al. Early and late complications associated with transcatheter occlusion of secundum atrial septal defect. J Am Coll Cardiol 2002;39:10611065 .
7. Lloyd TR, Rao PS, Beekman RH, et al. Atrial septal defect occlusion with the buttoned device (a multi-institutional U.S. trial). Am J Cardiol 1994;73:286-291.

8. Mellert F, Preusse CJ, Haushofer M, et al. Surgical management of complications caused by transcatheter ASD closure. Thorac Cardiovasc Surg 2001;49:338-342.

9. Lloyd T, Vermillion R, Zamora R, Ludomirsky A, Beekman R. Influence of echocardiographic guidance on positioning of the buttoned occluder for transcatheter closure of atrial septal defects. Echocardiography 1996;13:117-121.

10. Arabia FA, Rosado LJ, Lloyd TR, Sethi GK. Management of complications of Sideris transcatheter devices for atrial septal defect closure. J Thorac Cardiovasc Surg 1993;106:886-888.

11. Berdat PA, Chatterjee T, Pfammatter J, Windecker S, Meier B, Carrel T. Surgical management of complications after transcatheter closure of an atrial septal defect or patent foramen ovale. J Thorac Cardiovasc Surg 2000;120:1034-1039. 